\title{
Conservação de manga com uso de fécula de mandioca preparada com extrato de cravo e canela
}

\author{
Miryan Franciele Pereira Serpa ${ }^{1}$, Ariane Castricini ${ }^{2}$,Gisele Polete Mitsobuzi ${ }^{3}$, Ramilo Nogueira Martins ${ }^{4}$, \\ Martielle Fernandes Batista ${ }^{5}$, Thiago Henrique de Almeida ${ }^{6}$ \\ http://dx.doi.org/10.1590/0034-737X201461060013
}

\section{RESUMO}

O objetivo deste trabalho foi avaliar a conservação pós-colheita de mangas 'Palmer' e o desenvolvimento de fungos fitopatogênicos nos frutos, após o revestimento por fécula de mandioca, preparada com águas de cravo e de canela. Para execução do trabalho, foram utilizados cinco tratamentos: $\mathrm{T}_{1=}$ testemunha (sem revestimento), $\mathrm{T}_{2=}$ imersão em solução de fécula a 3\%, preparada com água de cravo, por 12 horas, $\mathrm{T}_{3=}$ imersão em solução de fécula a $3 \%$, preparada com água de canela, por 12 horas, $\mathrm{T}_{4=}$ imersão em solução de fécula a 3\%, preparada com água destilada, $\mathrm{T}_{5=}$ imersão em solução de fécula a $3 \%$, preparada com água de canela, por 24 horas e $\mathrm{T}_{6=}$ imersão em solução de fécula a 3\%, preparada com água de cravo, por 24 horas. Esses frutos foram armazenados em câmara a $25^{\circ} \mathrm{C}$, por dez dias. Foram avaliados perda de matéria fresca, firmeza, cores interna e externa, pH, sólidos solúveis, ácido ascórbico, acidez titulável e identificação de patógenos presentes nas lesões. O revestimento de mangas 'Palmer' por fécula de mandioca, preparada com águas de cravo ou de canela, não influenciou na maioria das características de pós-colheita avaliadas. Entretanto, o revestimento assim preparado reduz a percentagem de fitopatógenos durante o armazenamento, sendo o extrato de cravo mais eficiente que o extrato de canela.

Palavras-chave: Mangifera indica, fungos, revestimento comestível.

\section{ABSTRACT}

\section{Mango conservation using cassava starch prepared with extract of clove and cinnamon}

The objective of this study was to evaluate the postharvest conservation of 'Palmer' mangos and the development of pathogenic fungi in fruits, after cassava starch coating prepared with cloves and cinnamon water. Five treatments were used in the experiment: $\mathrm{T}_{1}=$ control (uncoated); $\mathrm{T}_{2}=$ immersion in $3 \%$ starch solution prepared with water clove for 12 hours; $\mathrm{T}_{3}=$ immersion in $3 \%$ starch solution prepared with cinnamon water for 12 hours; $\mathrm{T}_{4}=$ immersion in $3 \%$ starch solution prepared with distilled water; $\mathrm{T}_{5}=$ immersion in $3 \%$ starch solution prepared with cinnamon water and $\mathrm{T}_{6}=$ immersion in $3 \%$ starch solution prepared with clove water for 24 hour. These fruits were stored in a chamber at $25^{\circ} \mathrm{C}$ for 10 days. The following were evaluated in the experiment: loss of fresh mass, firmness, external and internal color, $\mathrm{pH}$, soluble solids, ascorbic acid, titratable acidity, and identification of pathogens present in the wounds. The coating of mangoes 'Palmer' by cassava starch prepared with clove or cinnamon water did not affect the majority of postharvest characteristics evaluated. However, the coating prepared in such manners reduces the percentage of pathogens during storage. Moreover, the clove extract was more efficient then cinnamon extracts.

Key words: edible coating, fungi, Mangifera indica.

Recebido para publicação em 15/04/2013 e aprovado em 21/05/2014

'Engenheira-Agrônoma. Universidade Estadual do Sudoeste da Bahia, Estrada do Bem Querer, Km 4, Vitória da Conquista, Bahia, Brasil. miryanpserpa@ yahoo.com.br (autora para correspondência).

${ }^{2}$ Engenheiros-Agrônomos, Doutores. Empresa de Pesquisa Agropecuária de Minas Gerais, Rodovia MGT Km 155, Zona Rural, Nova Porteirinha, Minas Gerais, Brasil. ariane@epamig.com ${ }^{3}$ Engenheira-Agrônoma, Doutora. Universidade Estadual de Montes Claros, Avenida Reinaldo Viana, 2630, Bico da Pedra, Brasil. gisele.mizobutsi@unimontes.br ${ }^{4}$ Engenheira-Agrônoma. Universidade Estadual de Montes Claros, Avenida Reinaldo Viana, 2630, Bico da Pedra, Brasil. martiellefernandes@hotmail.com

${ }^{5}$ Graduando em zootecnia. Universidade Estadual de Montes Claros, Avenida Reinaldo Viana, 2630, Bico da Pedra, Brasil. thiagohenriq3@gmail.com 


\section{INTRODUÇÃO}

O Brasil é um grande produtor mundial de manga, segundo o Instituto Brasileiro de Geografia e Estatística (IBGE,2012), em 2012 foram destinados a colheita de manga área de 73.690 hectares, onde foram produzidos 1.175.735 toneladas da fruta.

A manga Palmer é semianã, originada na florida em 1945. Os frutos possuem casca roxa quando "de vez" e vermelha quando maduros. A polpa é amarela, firme, bom sabor (Brix $\left.{ }^{\circ} 21,6\right)$, com pouca ou nenhuma fibra. Apresenta boa vida de prateleira e é bem aceita no mercado interno (Costa \& Santos, 2004). Já foram realizados diversos trabalhos utilizando 1-MCP, óleo de soja, embalagens plásticas e tratamento hidrotérmico + fungicidas (Pfaffenbach, 2003; Junqueira et al., 2004; Hojo et al., 2009; e Santos et al., 2010) com o objetivo de melhorar a qualidade pós colheita da manga 'Palmer'. Em trabalho realizado por Santos et al., (2010) a manga Palmer conservada sob temperatura de $23^{\circ} \mathrm{C}$ e UR de $65 \%$ apresentou aceitação comercial por até 10 dias, já em condições refrigeradas a $12^{\circ} \mathrm{C}$ ela manteve a qualidade até os 28 dias.

Visando melhorar a qualidade de frutos e atender as exigências em qualidade desejada pelo mercado consumidor, devem ser realizados estudos que desenvolvam e avaliem tecnologias que irão auxiliar na conservação póscolheita dos frutos, aumentando assim a sua vida útil de prateleira e diminuindo as grandes perdas pós-colheita. Vários trabalhos mostram a eficiência da atmosfera modificada (Hojo et al., 2007; Mizobutsi et al., 2012,) que pode fornecer bons resultados em termos de conservação, tem fácil aplicação e custo baixo.

Alguns produtos como cera de carnaúba e fécula de mandioca (Mota et al., 2006, Scanavaca Júnior, 2007), estão sendo testados para revestimentos, em diferentes concentrações, em frutos e hortaliças com a vantagem de serem naturais e não causarem danos ao meio ambiente nem ao homem, além de não terem período de carência.

De acordo com Azeredo (2003), a utilização de películas comestíveis tem sido bastante explorada para revestimento de frutas e hortaliças frescas, visando minimizar a perda de umidade e reduzir as taxas de respiração, além de conferir aparência brilhante e atraente.

Em pós-colheita deve-se considerar as podridões causadas pelo ataque de patógenos principalmente fungos, dentre esses os principais são: Colletotrichum gloeosporioides (antacnose) que é a principal doença em termos de expressão econômica (Junqueira et al., 2004) e podridão peduncular, causada por um complexo de fungos, destacando-se o Lasiodiplodia theobromae, que provocam grande depreciação e perdas nos frutos.
Os extratos vegetais vêm sendo estudados e/ou utilizados como alternativa ao uso de produtos químicos que, podem deixar resíduos nos alimentos, se não respeitado o período de carência.

Segundo Nurnberger \& Brunner (2002), a utilização de óleos e extratos naturais de plantas como pré-tratamentos para o controle de doenças pós-colheita está baseada na premissa de que estes representam a mistura de várias substâncias solúveis capazes de elicitar respostas de defesa em plantas ou agir diretamente sobre o fitopatógeno.

O objetivo deste trabalho foi avaliar a conservação pós-colheita de mangas 'Palmer' e o desenvolvimento de fungos fitopatogênicos após o revestimento por fécula de mandioca preparada com extrato aquoso de cravo e canela.

\section{MATERIAL E MÉTODOS}

Mangas 'Palmer' foram produzidas em pomar comercial, pertencente a fazenda Uvale, localizada no município de Nova Porteirinha no norte de Minas Gerais, com localização geográfica a $15^{\circ} 47^{\circ}$ de latitude sul e $43^{\circ} 17^{\prime}$ de longitude oeste e altitude de $500 \mathrm{~m}$. Foram colhidas fisiologicamente maduras, manualmente em agosto de 2011, com coloração da casca vermelha arroxeada e polpa correspondente ao grau 2 - 3 (mudança da cor da polpa de creme para amarela) da escala de coloração indicada pela Deutsche Gesellschaft für Technische Zusammenarbeit - GTZ (1992). O manejo do pomar estava de acordo com as normas da produção integrada de frutas (PIF). Logo após a colheita os frutos foram acondicionados em caixas plásticas protegidos por papel cortado e transportados para o Laboratório de PósColheita da EPAMIG - em Nova Porteirinha/MG.

No laboratório os frutos foram selecionados de acordo com a uniformidade da cor, o tamanho e a ausência de injúrias mecânicas e fisiológicas. Após a seleção foram lavados com água corrente e, posteriormente secos a temperatura ambiente.

Depois de secos os frutos foram submetidos aos tratamentos $T_{1}=$ testemunha sem imersão dos frutos na suspensão de fécula de mandioca, ou seja, sem revestimento, $\mathrm{T}_{2}=$ imersão em solução de fécula a $3 \%$ preparada com água de cravo, por 12 horas, $\mathrm{T}_{3=}$ imersão em solução de fécula $3 \%$ preparada com água de canela, por 12 horas, $\mathrm{T}_{4}=$ imersão em solução de fécula $3 \%$ preparada com água destilada, $\mathrm{T}_{5}=$ imersão em solução de fécula 3\% preparada com água de canela, por 24 horas e $\mathrm{T}_{6}=$ imersão em solução de fécula $3 \%$ preparada com água de cravo, por 24 horas.

Após a imersão por um minuto na solução foram colocados em recipiente telado para drenagem e seca- 
gem do excesso da solução. Posteriormente, procedeuse o acondicionamento em bandejas de poliestireno rígidas e armazenadas sob condição ambiente $\left(25 \pm 2{ }^{\circ} \mathrm{C}\right.$ e $65 \pm 5 \%$ UR), por 10 dias e, durante o período de armazenamento, foram amostrados 2 frutos por parcela, ao acaso, a cada dois dias.

As águas de cravo e canela foram preparadas da seguinte forma: $10 \mathrm{~g}$ de cravo deixados em descanso em 3 $\mathrm{L}$ de água destilada por $12 \mathrm{e} 24$ horas; $10 \mathrm{~g}$ de canela deixados em descanso em $3 \mathrm{~L}$ de água destilada por $12 \mathrm{e}$ 24 horas; posteriormente essa solução foi peneirada separando a porção líquida dos resíduos sólidos do cravo e da canela. As suspensões de fécula de mandioca a $3 \%$ foram preparadas com as águas de cravo e de canela, a mistura foi aquecida a $70^{\circ} \mathrm{C}$ para gelatinização do amido, o que aconteceu em aproximadamente (15 minutos), após a solução permaneceu em temperatura ambiente até o completo resfriamento.

As variáveis analisadas foram: a) Firmeza: Foi utilizado penetrômetro digital, com ponteira cilíndrica de $8 \mathrm{~mm}$. As medidas foram tomadas em um ponto do fruto com casca. As leituras foram expressas em Newton; b) Sólidos solúveis: foi avaliado utilizando-se um refratômetro de campo, com leitura expressas em ${ }^{\circ}$ Brix c) Acidez titulável: foi determinada por titulação com solução de $\mathrm{NaOH}$ 0,1 M, tendo-se como indicador a fenolftaleína $1 \%$ e os resultados expressos em gramas de ácido cítrico por $100 \mathrm{~g}$ de polpa (Instituto Adolfo Lutz, 1985); d) Ácido ascórbico: foi determinada de acordo com a AOAC (1997), e os resultados foram expressos em mg $100 \mathrm{~g}^{-1}$ de matéria fresca; e) Cor da polpa e da casca: foi obtida com o uso do colorímetro, sendo expressa pela luminosidade, cromaticidade e ângulo de cor

Para a determinação da porcentagem de perda de massa, foi considerada a diferença entre o peso inicial do fruto e aquele obtido a cada intervalo de tempo de amostragem, utilizando-se balança semianalítica, com precisão de $0,01 \mathrm{~g}$.

Nas análises fitopatolágicas, avaliou-se a incidência natural de patógenos, sob efeito dos tratamentos alternativos de cravo e canela, adicionados no revestimento por fécula de mandioca a 3\%. Foram selecionados frutos sem qualquer tipo de lesões e sem sintomas de doenças, cada tratamento contou com 15 frutos, as análises foram realizadas após o início dos sintomas de podridão, foi avaliado o número de frutos afetados e as colônias formadas (classificação por gênero).

Pedaços de tecido dos frutos de todos os tratamentos, com 0,5 mm de diâmetro foram retirados de lesões, na região de transição entre a área lesionada e a área sadia. Esses fragmentos foram superficialmente desinfestados com álcool $70 \%$ durante 30 segundos e hipoclorito de sódio 1,5\% durante 3 minutos e enxagua- dos três vezes em água destilada e esterilizada. Em seguida, os fragmentos do tecido foram transferidos para placas de Petri contendo o meio agar-água, sendo incubadas a $25^{\circ} \mathrm{C}$ durante três dias, em estufa incubadora do tipo BOD. Após esse período, discos de 0,5 mm foram retirados dos bordos das colônias e transferidos para tubos contendo meio BDA A partir da cultura pura realizou-se o preparo da lâmina para identificação do patógeno ao microscópio.

O delineamento utilizado foi inteiramente casualizado, disposto em esquema fatorial $6 \times 6$, com três repetições de dois frutos por parcela, o primeiro fator corresponde aos tratamentos (T1 a T6) e o segundo aos dias de armazenamento (0, 2, 4, 6, 8 e 10 dias). Os dados foram tabulados, e submetidos aos testes de normalidade e homogeneidade das variâncias e a análise de variância. $\mathrm{O}$ estudo dos efeitos significativos, dos tratamentos e dos dias foram feitos pelo teste Tukey a $5 \%$ de probabilidade e por análise de regressão, respectivamente.

\section{RESULTADOS E DISCUSSÃO}

Houve diferença significativa $(\mathrm{p}<0,05)$ dos valores de luminosidade (L) $\mathrm{e}^{\mathrm{o}}$ hue da casca dos frutos, em função dos tratamentos. As variáveis luminosidade, croma e ohue da polpa, firmeza, $\mathrm{pH}$, acidez titulável, ácido ascórbico variaram em função dos dias de armazenamento ( $\mathrm{p}<0,05)$. O croma da casca não foi influenciado pelos tratamentos e pelos dias de armazenamento ( $p$ $<0,05)$ e a perda de matéria fresca variou em função do efeito conjunto de tratamentos e dias $(\mathrm{p}<0,05)$.

Os resultados de coloração da casca permitiram observar que as mangas revestidas com fécula de mandioca preparada com água de cravo 24hs (T5) apresentaram maiores valores de luminosidade e ângulo de cor (Tabela 1). Estes frutos caracterizaram-se como mais claros que aqueles do tratamento testemunha (T1) e frutos revestidos com fécula preparada com água de canela $12 \mathrm{hs}$ (T3) e menos vermelhos que aqueles revestidos com fécula preparada com água destilada (T4). Entretanto, maior intensidade $\left({ }^{\circ}\right.$ hue $)$ da cor vermelha foi verificada na casca de frutos do T4, porém sem diferença significativa quando comparados aqueles do T1, T2, T3 e T6. O croma da casca não foi influenciado pelos tratamentos, o valor médio foi de 15,95.

Santos et al., (2010), verificaram evolução da coloração da cor casca de mangas 'Palmer' tratadas com fungicidas associados ou não com tratamento hidrotérmico, durante o armazenamento, pela redução dos valores de ${ }^{\circ}$ hue. Segundo Chitarra \& Chitarra (2005), as modificações na coloração dos frutos são decorrentes dos processos metabólicos, os quais correspondem a um dos principais critérios para a identificação do amadurecimento em frutas e hortaliças. 
De acordo com a Figura $2 \mathrm{~A}, \mathrm{~B}$ e C, verifica-se redução progressiva da luminosidade e do ${ }^{\circ}$ hue da polpa respectivamente, e aumento do croma, durante o armazenamento. De acordo com Lima (2009), as mudanças na coloração da polpa foram índices importantes no monitoramento do crescimento e da maturação da manga, sendo caracterizada por decréscimos na luminosidade e no ângulo de cor e por aumento na cromaticidade, estando de acordo com os resultados encontrados nesse trabalho.

A redução da luminosidade durante o armazenamento indica que a polpa das mangas tornou-se mais escura. A cromaticidade (C) indica a saturação em termos do pigmento da determinada cor, durante o armazenamento verificou-se aumento nos valores deste componente, esta tendência indica que a polpa dos frutos tornou-se mais brilhosa em função do amadurecimento.

O ângulo Hue ( $\left.{ }^{\circ} \mathrm{Hue}\right)$, da polpa da manga 'Palmer' reduziu, passando de $102,04^{\circ}$ para $89,06^{\circ}$, tornando-se, portanto, mais amarela durante o armazenamento. Essa redução está relacionada ao amadurecimento dos frutos, que na última avaliação apresentavam coloração amarelo-alaranjada.

Além das mudanças na coloração, a firmeza é uma importante transformação que acontece durante o amadurecimento dos frutos, pois ocorre o amaciamento da polpa com a perda da firmeza. Entre os tratamentos a firmeza não se diferenciou, houve diferença para os dias de armazenamento sendo que no dia zero os frutos estavam mais firmes, com 188,55 $\mathrm{N}$ e no último dia de armazenamento, 81,95 N (Figura $3 \mathrm{~A}$ ). Com o aumento da respiração climatérica e produção de etileno durante a maturação dos frutos climatéricos, como a manga, há indução de enzimas degradadoras de parede celular, como a poligalacturonase e pectinametilesterase. A degradação da parede torna os frutos amolecidos, com menor firmeza e consequentemente mais frágeis ao transporte e com menor vida de prateleira.

$\mathrm{O}$ teor de ácido ascórbico aumentou até aproximadamente 4,5 dias de armazenamento (Figura 3 B), após foi observada redução até o final do período. Assim como no presente trabalho, Hoa et al., (2008), não verificaram efeito de diferentes revestimentos sobre o teor de ácido ascórbico de mangas. Entretanto, tendência semelhante de redução deste componente, foi verificada por Santos et al., (2010), durante 12 dias de armazenamento de mangas 'Palmer'.

$\mathrm{O} \mathrm{pH}$, e a acidez titulável da polpa foram influenciados pelos dias de armazenamento (Figura 4 A, B e C) e o teor de sólidos solúveis, também pelos efeitos isolados de tratamentos. O pH e o teor de sólidos solúveis aumentaram durante o armazenamento, em consequiência ao aumento de $\mathrm{pH}$, a acidez titulável reduziu. Estas variações tornam os frutos mais agradáveis ao paladar, pela redução da acidez e aumento dos sólidos solúveis. Santos et al., (2010), também observaram redução da acidez titulável e aumento dos sólidos solúveis durante o amadurecimento de mangas 'Palmer'. Segundo Chitarra \& Chitarra (2005), com a redução da acidez ocorre um aumento dos valores de $\mathrm{pH}$, comportamento decorrente do consumo dos ácidos orgânicos no processo respiratório. O consumo de ácidos orgânicos no processo respiratório é o principal responsável pela diminuição da acidez e o aumento do pH (Rocha et al., 2001).

Durante a maturação da manga o pH aumenta gradativamente, a acidez diminui até atingir um teor ácido agradável que combinado com o teor de açúcares solúveis, proporciona o paladar característico do fruto, podendo variar de uma variedade para outra (Evangelista et al.,1999).

Segundo Chitarra \& Chitarra (2005), geralmente o teor de sólidos solúveis aumentam com o transcorrer da maturação, seja por biossíntese, pela degradação de polissacarídeos, ou ainda pela excessiva perda de água dos frutos ocorrendo acúmulo dos mesmos. O processo de desidratação do fruto, bem como a degradação da parede celular, pode elevar a concentração dos açúcares totais.

Os valores médios do teor de sólidos solúveis em função dos tratamentos estão apresentados na Tabela 1. Fru-

Tabela 1. Luminosidade (L) e ângulo de cor (Hue) da casca e sólidos solúveis da polpa de mangas 'Palmer', revestidas por fécula de mandioca preparada com água de cravo ou de canela e armazenadas à $25^{\circ} \mathrm{C}$ e UR $65 \%$

\begin{tabular}{lccc}
\hline \multirow{2}{*}{ Tratamentos } & \multicolumn{3}{c}{ Variáveis } \\
\cline { 2 - 4 } & $\mathbf{L}$ & ${ }^{\mathbf{o}}$ Hue & Sólidos Solúveis \\
\hline Testemunha (sem revestimento) & $38,59 \mathrm{~b}$ & $75,70 \mathrm{ab}$ & $4,90 \mathrm{a}$ \\
Água de cravo 12hs+fécula 3\% & $40,27 \mathrm{ab}$ & $72,83 \mathrm{ab}$ & $4,13 \mathrm{ab}$ \\
Água de canela 12hs+fécula 3\% & $38,37 \mathrm{~b}$ & $69,23 \mathrm{ab}$ & $4,46 \mathrm{ab}$ \\
Água destilada+fécula 3\% & $39,42 \mathrm{ab}$ & $57,82 \mathrm{~b}$ & $4,06 \mathrm{~b}$ \\
Água de canela 24hs+fécula 3\% & $41,65 \mathrm{a}$ & $78,41 \mathrm{a}$ & $4,58 \mathrm{ab}$ \\
Água de cravo 24hs+fécula 3\% & $40,21 \mathrm{ab}$ & $66,28 \mathrm{ab}$ & $4,30 \mathrm{ab}$ \\
DMS & 2,56 & 18,70 & 0,62 \\
\hline
\end{tabular}

Médias seguidas da mesma letra na coluna não diferem significativamente, pelo teste de Tukey $(\mathrm{P} \leq 0,05)$.

Rev. Ceres, Viçosa, v. 61, n.6, p. 975-982, nov/dez, 2014 


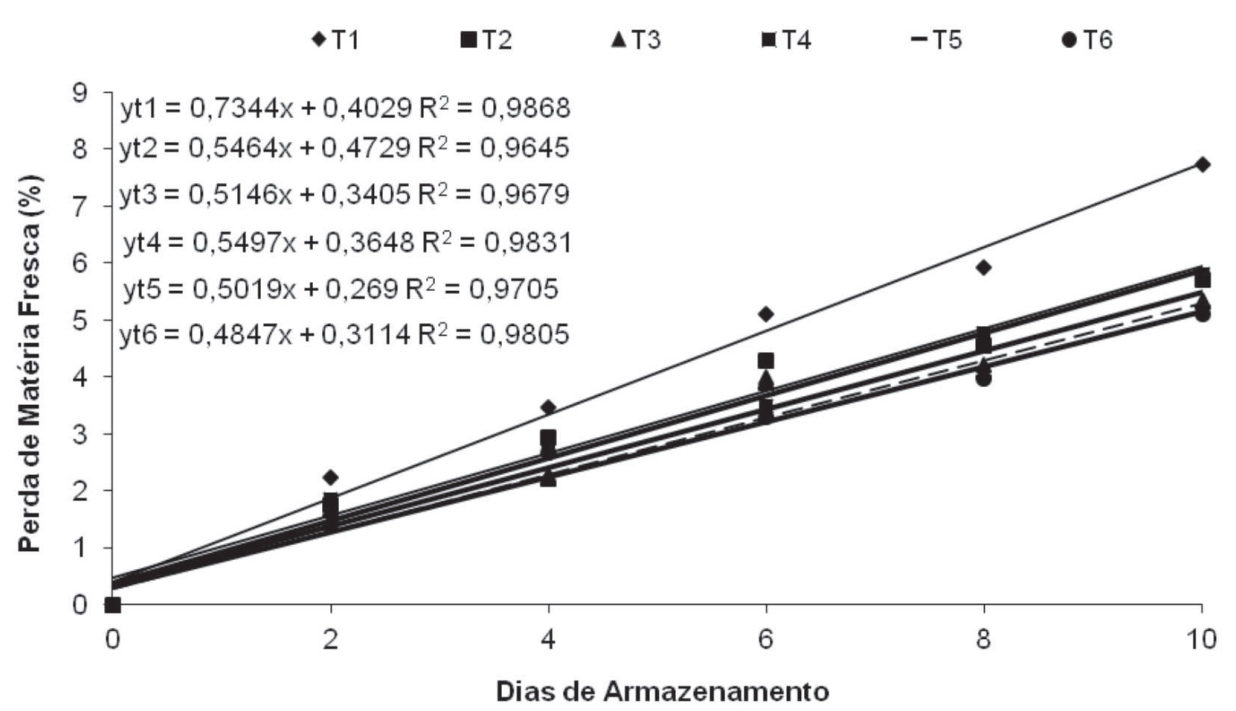

Figura 1. Perda de matéria fresca de manga "Palmer", revestida por fécula de mandioca preparada com água de cravo ou canela armazenados a $25^{\circ}$, e UR $65 \%$. Onde $\mathrm{T}_{1}=$ testemunha sem imersão dos frutos na suspensão de fécula de mandioca, $\mathrm{T}_{2}=\mathrm{imersão}$ em solução de fécula a $3 \%$ preparada com água de cravo, por 12 horas, $\mathrm{T}_{3}=$ imersão em solução de fécula $3 \%$ preparada com água de canela, por 12 horas, $\mathrm{T}_{4}=$ imersão em solução de fécula $3 \%$ preparada com água destilada, $\mathrm{T}_{5}=$ imersão em solução de fécula $3 \%$ preparada com água de canela, por 24 horas e $\mathrm{T}_{6}=$ imersão em solução de fécula $3 \%$ preparada com água de cravo, por 24 horas.

tos sem revestimento (T1) tiveram maiores teores que frutos do T4, mas sem diferença significativa em relação aqueles dos demais tratamentos. O preparo das suspensões de fécula de mandioca para o revestimento, com as águas de cravo e canela pode ter induzido o amadurecimento, já que os frutos tiveram maiores valores de ${ }^{\circ}$ Brix.

Houve aumento da perda de matéria fresca durante os dias de armazenamento, em todos os frutos independente do tratamento (Figura 1). Entretanto, nos frutos sem revestimento a proporção de perda no último dia de armazenamento foi mais acentuada. Em frutos revestidos por fécula de mandioca a $3 \%$, independente do tipo de água de preparo, também ocorreu perda, mas em menor amplitude comparados com aqueles sem revestimento. A película formada pela fécula de mandioca sob os frutos é semipermeável, ou seja permitiu que os frutos continuassem respirando, conferindo, mesmo após 10 dias de armazenamento em temperatura ambiente, melhor aspecto com aparência menos enrugada.

Os revestimentos podem exercer função de atmosfera modificada, alterando a relação da composição gasosa disponível aos frutos; geralmente ocorre redução da disponibilidade de $\mathrm{O}_{2}$ e aumento da concentração de $\mathrm{CO}_{2}$, interferindo na respiração climatérica. Deve-se considerar também, que a película de fécula formada sob os frutos pode atuar como barreira a perda de água, que está associada a transpiração, responsável pela perda de água. A transpiração, caracterizada pela perda de água leva ao murchamento e amolecimento dos tecidos, tornando os frutos mais susceptíveis a deteriorações, bem como alterações no sabor e aparência (Hojo, 2007).
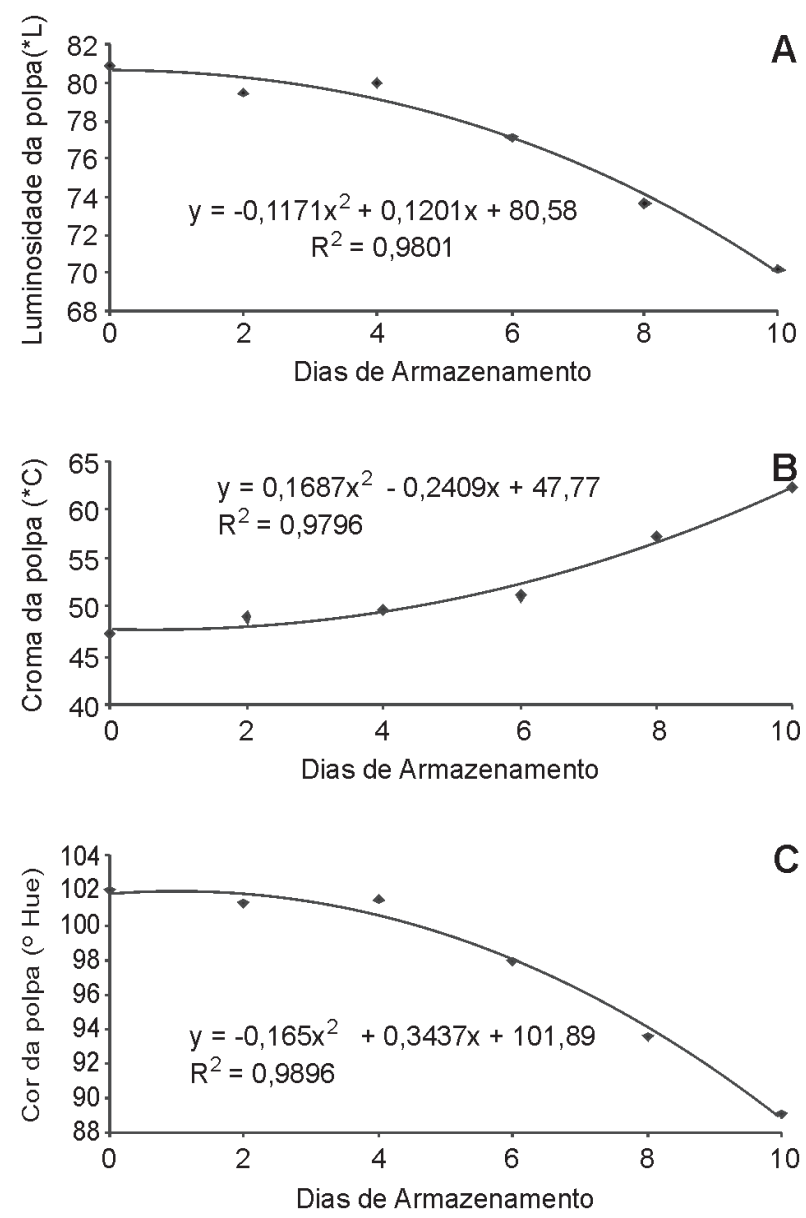

Figura 2. Luminosidade (A), cromaticidade (C) e cor $\left({ }^{\circ} \mathrm{Hue}\right)$ da polpa de mangas 'Palmer' revestidas por fécula de mandioca preparada com água de cravo ou de canela, armazenadas por 10 dias.

Rev. Ceres, Viçosa, v. 61, n.6, p. 975-982, nov/dez, 2014 
Não houve diferença significativa entre os tratamentos quanto a perda a matéria fresca nos dias 0 e 2 de armazenamento ( $\mathrm{p}<0,05)$, as diferenças surgiram a partir do quarto dia, com menor valor para frutos revestidos por fécula de mandioca preparada com água de canela 24, por horas. No sexto e oitavo dia os valores de perda de matéria fresca foi semelhante entre os tratamentos, sendo maior no décimo dia em frutos sem revestimento.

Segundo Pereira et al., (2006) a suspensão de fécula de mandioca nas concentrações de 1 e $3 \%$ reduziram a perda de massa em manga Tommy Atkins', com efeito mais acentuado da concentração de $3 \%$.

Com o amadurecimento do fruto, diminui a acidez total titulável e aumentara os teores de sólidos solúveis totais, a relação SS/AT e o pH, em função da respiração e/ou da conversão de ácidos orgânicos em açúcares (Chitarra \& Chitarra, 2005).

As lesões observadas foram causadas por Lasiodiplodia theobromae, Colletotrichum gloeoisporioides e Rizophus spp. e começaram a surgir a partir do $15^{\circ}$ dia de armazenamento. Frutos tratados com fécula de mandioca a $3 \%$ preparada com água destilada foram os mais atacados $47 \%$, seguido pela testemunha (sem revestimento), $40 \%$ afetados (Tabela 2). Frutos tratados com extrato de cravo e canela tiveram menor porcentagem de lesões causadas por Colletotrichum gloeoisporioides, e Lasiodiplodia theobromae, sendo que o tempo de permanência do cravo e da canela na água não interferiu na capacidade dos mesmos de diminuir o desenvolvimento de fungos
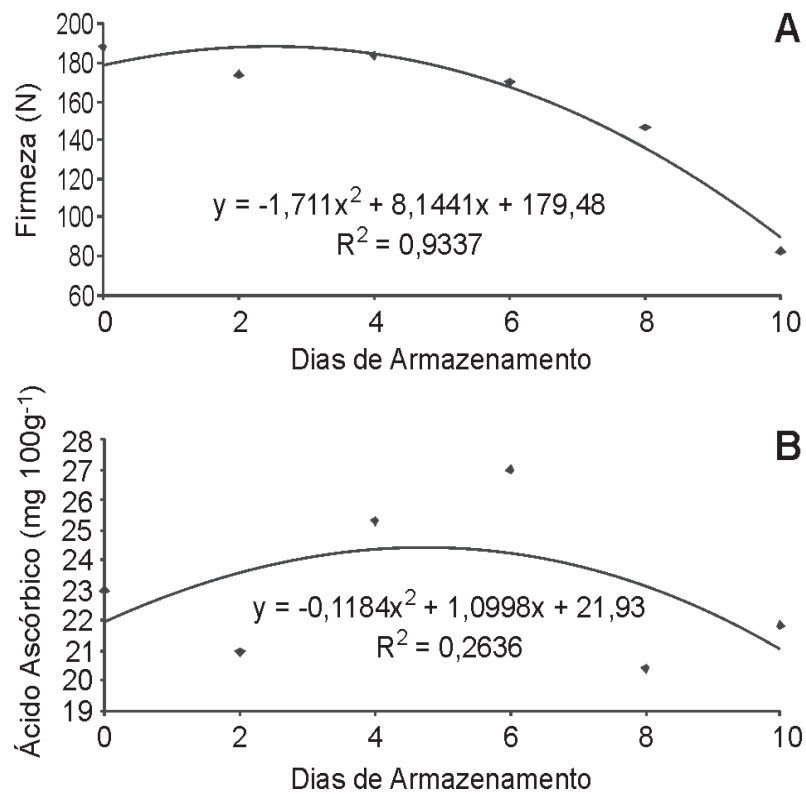

Figura 3. Firmeza (A) e ácido ascórbico (B) da polpa de mangas 'Palmer' revestidas por fécula de mandioca preparada com água de cravo ou de canela, armazenadas por 10 dias. fitopatogenicos (Tabela 2). Frutos revestidos por fécula preparada com água de cravo não foram afetados por lesões de Lasiodiplodia theobromae.

$\mathrm{O}$ fato da maior porcentagem de frutos lesionados terem sido encontrados na testemunha e no tratamento água destilada+fécula 3\%, pode ter ocorrido porque estes frutos não contavam com a proteção do extrato de cravo e canela que possuem em sua composição substâncias como cinamaldeído que atua como fungicida. Tanto o cravo como a canela independente do tempo de permanência na água teve a mesma eficiência em diminuir o número de frutos lesionados por Colletotrichum gloeosporioides.

$\mathrm{O}$ ataque de Lasiodiplodia theobromae também foi menor naqueles frutos tratados com extrato de cravo e canela. O cravo, imerso por 12 ou 24 horas na água inibiu em $100 \%$ o aparecimento de Lasiodiplodia theobromae, a canela por 24 horas na água teve maior efeito que por 12 horas sobre este patógeno. Só houve o aparecimento de Rhizophus no tratamento cravo na água por 24 horas.
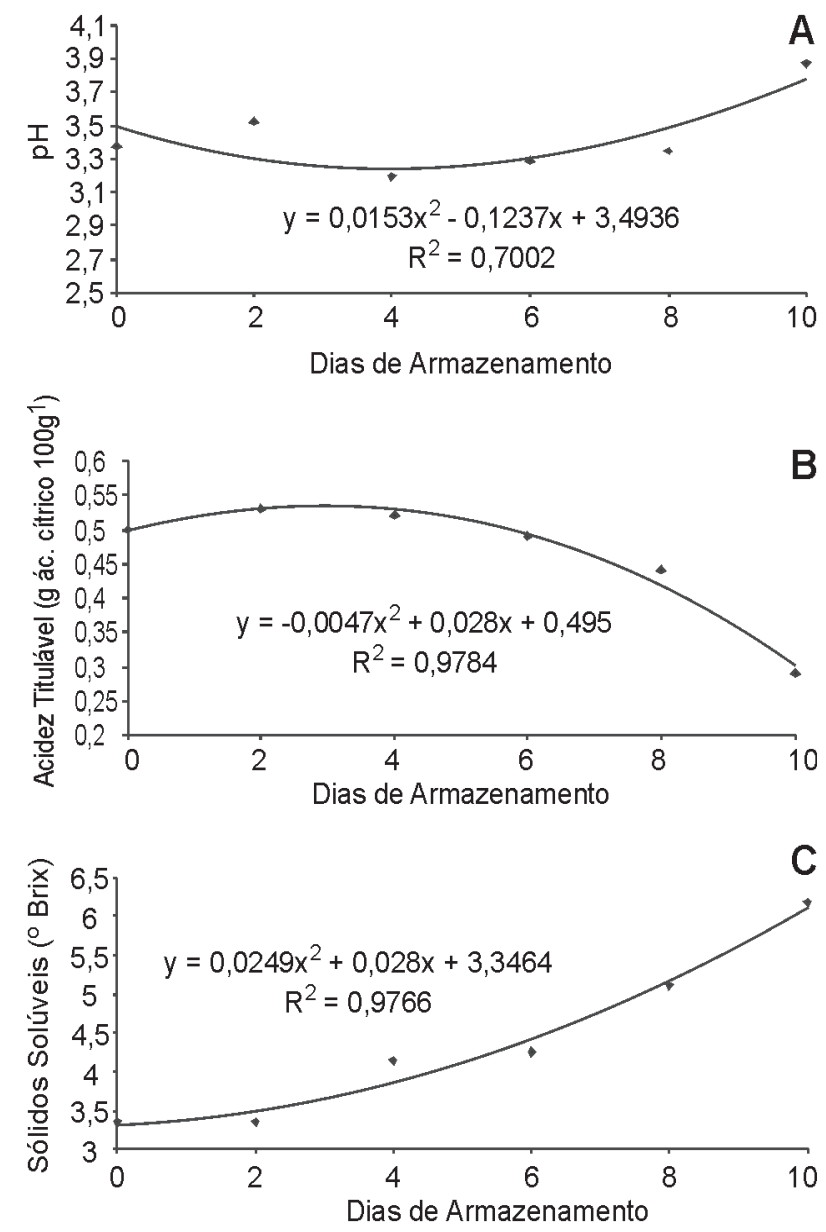

Figura 4.pH, acidez titulável e sólidos solúveis da polpa de mangas 'Palmer' revestidas por fécula de mandioca preparada com água de cravo ou de canela, armazenadas por 10 dias. 
Tabela 2. Porcentagem de frutos tratados com fécula, extrato de cravo e canela, armazenados a $25^{\circ}$, UR $65 \%$, por 17 dias, atacados por fungos fitopatogenicos

\begin{tabular}{lcccc}
\hline Tratamento & \% C. gloeosporioides & \% L. theobromae & \% Rhizopus & \% Normais \\
\hline Testemunha & 33 & 7 & 0 & 60 \\
Água de cravo 12hs+fécula 3\% & 14 & 0 & 0 & 86 \\
Água de canela 12hs+fécula 3\% & 14 & 7 & 0 & 79 \\
Água destilada+fécula 3\% & 33 & 14 & 0 & 53 \\
Água de canela 24hs+fécula 3\% & 14 & 14 & 0 & 78 \\
Água de cravo 24hs+fécula 3\% & 14 & 0 & 20 & 66 \\
\hline
\end{tabular}

De acordo com Abreu (2006), que trabalhou com tomate, os resultados encontrados no trabalho confirmam que os óleos essenciais de cravo da índia e canela, apresentaram efeito inibitório contra fungos como observado em outras bibliografias, e em Alternaria solani. Isso se deve aos componentes existentes nos óleos. $\mathrm{O}$ óleo essencial de cravo da índia e canela inibiram "in vitro" o desenvolvimento micelial e conidial de $A$. solani a partir da menor concentração de $750 \mu \mathrm{L} / \mathrm{L}^{-1}$.

Montes-Belmont \& Carvajal (1998), adicionando óleo de canela a sementes de milho contra A. flavus, observaram inibição no crescimento do fungo e que os dois componentes do óleo, cinnamaldehidos e o eugenol também demonstraram propriedades inibitórias contra o fungo.

Ouattara et al., (1997), ressaltam que o óleo essencial de canela tem efeito inibidor da deterioração de alimentos por organismos. Como têm demonstrado Singh et al. (1995) em seus trabalhos, o óleo da casca tem propriedades fungitóxicas contra micoses do aparelho respiratório e Aspergillus niger, e contra A fumigatus, A. nidulans e A. flavus.

\section{CONCLUSÕES}

O revestimento de mangas 'Palmer' por fécula de mandioca preparada com água de cravo ou de canela não influenciou na maioria das características de pós-colheita avaliadas. Entretanto o revestimento assim preparado reduz a percentagem de fitopatógenos durante o armazenamento, sendo o extrato de cravo o mais eficiente.

\section{REFERÊNCIAS}

Abreu CLM (2006) Controle de Alternaria solani em tomateiro (Lycopersicon esculentum) com óleos essenciais. Tese de Doutorado. Universidade Estadual Paulista, Jaboticabal. 150p.

AOAC (1997) Association of Official Analytical Chemests. Official methods of analysis of AOAC international. $16^{\text {th }}$ ed. Gaithersburg, AOAC. 1141p.

Azeredo HMC de (2003) Películas comestíveis em frutas conservadas por métodos combinados: potencial da aplicação. Curitiba, Embrapa. 270p. (Boletim do CEPPA).
Chitarra MIF \& Chitarra AB (2005) Pós-colheita de frutas e hortaliças:

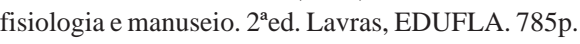

Costa JG \& Santos CAF (2004) Cultivares. In: Mouco MAC (Ed.) Cultivo da Mangueira. Petrolina, Embrapa Semi-Árido. Disponível em: <http://www.cpatsa.embrapa.br/sistema_producao/spmanga/ cultivares.htm>. Acessado em: 20 de maio de 2012.

Evangelista RE (1999) Qualidade de mangas "Tommy Atkins" armazenadas sob refrigeração e tratadas com cloreto de cálcio na pré-colheita. Tese de Doutorado. Universidade Federal de Lavras, Lavras. 129p.

Deutsche Gesellschaft Für Technische Zusammenarbeit (1992) Manual de exportación: frutas tropicales y hortalizas. Eschborn, GTZ. 34p.

Hoa TT \& T Ducamp MN (2008) Effects of different coatings on biochemical changesof 'Cat Hoa Loc' mangoes in storage. Postharvest Biology and Technology, 48:150-152.

Hojo ETD, Cardoso AD, Hojo RH, Boas EV de BV \& Alvarenga MAR (2007) Uso de películas de fécula de mandioca e PVC na conservação pós-colheita de pimentão. Ciência e Agrotecnologia, 31:184-190.

Instituto Adolfo Lutz (1985) Normas analíticas do Instituto Adolfo Lutz. Métodos químicos e físicos para análise de alimentos. São Paulo, IMESP. 533p.

IBGE - Instituto Brasileiro de Geografia e Estatística (2010) Produção Agrícola Municipal. Disponível em: 〈http://www.cnpmf.embrapa.br/ planilhas/Manga_Brasil_2009.pdf>. Acessado em: 20 de setembro de 2011.

Junqueira NTV, Chaves R da C, Nascimento AC do, Ramos VHV, Peixoto JR \& Junqueira LP (2004) Efeito do óleo de soja no controle da antracnose e na conservação da manga cv. palmer em pós-colheita. Revista Brasileira de fruticultura, 26:222-225.

Lima MAC de, Silva Alda \& Azevedo SSN (2009) Evolução de indicadores do ponto de colheita em manga 'Tommy Atkins' durante o crescimento e a maturação, nas condições do vale do São Francisco, Brasil. Ciências agrotecnica, 33:765-770.

Mizobutsi GP, Silva JM da, Mizobutsi EH, Rodrigues MLM, Lopes RS, Fernandes MB \& Oliveira FS (2012) Conservação de pinha com uso de atmosfera modificada e refrigeração. Revista Ceres, 59:751-757.

Montes-Belmont R \& Carvajal M (1998) Control of Aspergillus flavus in maize with plant essential oils and their components. Journal of Food Protection, 6:616-619.

Mota WF da, Salomão LCC, Neres CRL, Mizobutsi GP \& Neves LL de M (2006) Uso de cera de carnaúba e saco plástico poliolefínico na conservação pós-colheita do maracujá-amarelo. Revista Brasileira de Fruticultura, 28:190-193.

Nurnberger T \& Brunner F (2002) Innate Immunity in plants and animals: emerging parallels between the recognition of general eliciadores and pathogen-associated molecules. Current Opinion in Plant Biology, 5:318-324.

Rev. Ceres, Viçosa, v. 61, n.6, p. 975-982, nov/dez, 2014 
Ouattara B, Simard RE, Holley RA, Piette GJ-P \& Bégin A (1997) Antibacterial activity of selected fatty acids and essential oils agains six meat spoilage organisms. International Journal of Food Microbiology, 37:155-162.

Pereira MEC, Bispo AS da S, Santos AS da R, Santos DB dos, Santos, SB dos \& Santos VJ dos (2006) Amadurecimento de mamão Formosa com revestimento comestível à base de fécula de mandioca. Ciência e Agrotecnologia, 30:1116-1119.

Rocha RHC, Menezes JB, Morais EA de, Silva GG da, Ambrósio MM de Q \& Alvez MZ (2001) Uso do índice de degradação de amido na determinação da maturidade da manga 'Tommy Atkins". Revista Brasileira de Fruticultura, 23:302-305.
Santos LO, Durigan JF, Martins RN \& Morgado CMA (2010) Conservação e qualidade de mangas 'Palmer' submetidas a tratamento com fungicidas e hidrotérmico. Ciência e Agrotecnologia, 34:15141521 .

Scanavaca Júnior L, Fonseca N \& Pereira MEC (2007) Uso de fécula de mandioca na pós-colheita de manga 'surpresa'. Revista Brasileira de Fruticultura, 29:67-71.

Singh BM (1967) Inducing sporulation in different straing of Alternaria solani. Mycopathology et Mycology Applied, 31:144-50.

Rev. Ceres, Viçosa, v. 61, n.6, p. 975-982, nov/dez, 2014 